\title{
The golden polytetrafluoroethylene parachute
}

\author{
Tomasz A. Timek, MD, PhD
}

\author{
From the Division of Cardiothoracic Surgery, Spectrum Health, Michigan State University College of Human \\ Medicine, Grand Rapids, Mich. \\ Disclosures: Author has nothing to disclose with regard to commercial support. \\ Received for publication Nov 16, 2018; accepted for publication Nov 16, 2018; available ahead of print Jan 7 , \\ 2019. \\ Address for reprints: Tomasz A. Timek, MD, PhD, Division of Cardiothoracic Surgery, Spectrum Health, Mich- \\ igan State University College of Human Medicine, 100 Michigan Ave NE, Grand Rapids, MI (E-mail: tomasz. \\ timek@spectrumhealth.org). \\ J Thorac Cardiovasc Surg 2019;157:943-4 \\ $0022-5223 / \$ 36.00$ \\ Copyright (c) 2018 by The American Association for Thoracic Surgery \\ https://doi.org/10.1016/j.jtcvs.2018.11.061
}

Mitral valve repair has been firmly established as the gold standard for addressing degenerative mitral valve pathology, ${ }^{1}$ with reliable and standardized repair techniques of posterior leaflet prolapse. Anterior leaflet pathology still remains a formidable surgical challenge, however, and is associated with inferior long-term outcomes. ${ }^{2}$ Artificial polytetrafluoroethylene chordae have been introduced to aid reconstruction of complex mitral lesions, ${ }^{3}$ but proper determination of chordal length and the number of chordae needed requires significant experience and mature judgment. In the current issue of the Journal, Chawla and colleagues ${ }^{4}$ present an expanded polytetrafluorethylene multichordal device as a potential tool to facilitate repair of complex mitral lesions. Chawla and colleagues ${ }^{4}$ implanted the device in 7 pigs, with 6 surviving at least 150 days and 5 having mild or less mitral regurgitation at distant follow-up. The investigators demonstrated good biocompatibility of the polytetrafluoroethylene device and maintenance of valvular competence after transection of native marginal chordae. Chawla and colleagues ${ }^{4}$ are to be congratulated on an ambitious large animal project and detailed histopathologic examination of the explanted valves. Before the device beholds the goal of standardizing anterior leaflet repair, however, several questions remain unanswered. Although repeated sizing may be avoided, the proposed technique is still "hampered" by the need to properly judge neochordal length of the device. In the experiment, Chawla and colleagues ${ }^{4}$ used the native "reference chordae" as a guide; these were normal pig valves, however, and identifying reference chordae in complex degenerative disease is neither simple nor obvious. Chawla and colleagues ${ }^{4}$ propose that for complex lesions 1 or 2 devices could potentially address entire valvular pathology, but this would introduce significantly more foreign material than standard repair, perhaps negating the reduction in infectious complications that is usually associated with mitral valvuloplasty. The study did not include a control arm with spectrum. will make it golden.

\section{References}

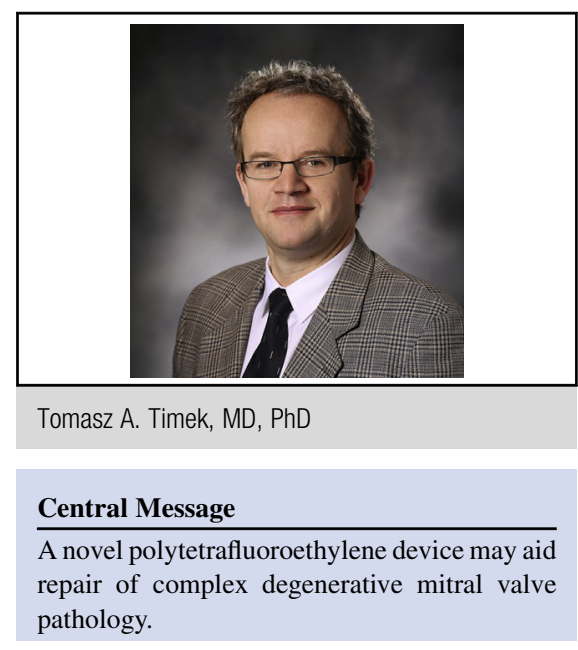

See Article page 932.

mitral repair performed with standard polytetrafluoroethylene chordae, and therefore a direct comparison of biocompatibility and clinical efficacy is not possible. The single animal that showed development of significant mitral regurgitation at distant follow-up deserves closer examination because of the dehiscence of the device at the leaflet insertion site. Chawla and colleagues ${ }^{4}$ attribute this event to erroneous transection of an adjacent strut chordae; however, transection of secondary chordae has been shown both clinically ${ }^{5}$ and experimentally ${ }^{6}$ not to affect valvular competence. Although leaflet stress distribution could be affected, ${ }^{7}$ the device should be able to withstand such fluctuations across a physiologic

Reliable and reproducible techniques for posterior leaflet repair are a part of most surgeons' technical armamentarium, but repair of complex anterior leaflet pathology remains a formidable challenge because surgical techniques are less standardized. This report builds on the concept of artificial chordae replacement in offering a potential standard device for complex valve pathology. Chawla and colleagues ${ }^{4}$ have taken the first step of demonstrating safety and biocompatibility of the mitral polytetrafluoroethylene parachute; proven clinical efficacy

1. Carpentier A. Cardiac valve surgery - the "French correction." J Thorac Cardiovasc Surg. 1983;86:323-37. 
2. Javadikasgari H, Mihaljevic T, Suri RM, Svensson LG, Navia JL, Wang RZ, et al. Simple versus complex degenerative mitral valve disease. J Thorac Cardiovasc Surg. 2018; 156:122-9.

3. Frater RW, Vetter HO, Zussa C, Dahm M. Chordal replacement in mitral valve repair. Circulation. 1990;82(5 Suppl):IV125-30.

4. Chawla SK, Frater RW, Cunningham M. Padala M. Performance and healing of an expanded polytetrafluoroethylene multichordal device at 6 months after repair of mitral leaflet flail in swine. J Thorac Cardiovasc Surg. 2019;157: 932-40.
5. Borger MA, Murphy PM, Alam A, Fazel S, Maganti M, Armstrong S, et al. Initial results of the chordal-cutting operation for ischemic mitral regurgitation. J Thorac Cardiovasc Surg. 2007;133:1483-92.

6. Timek TA, Nielsen SL, Green GR, Dagum P, Bolger AF, Daughters GT, et al. Influence of anterior mitral leaflet second-order chordae on leaflet dynamics and valve competence. Ann Thorac Surg. 2001;72:535-40; discussion 541

7. He Z, Jowers CW. Effect of mitral valve strut chord cutting on marginal chord tension. J Heart Valve Dis. 2008;17:628-34. 